\title{
Transplantation in low resource countries
}

\author{
L. Faulkner, N. Yaqub, ${ }^{2}$ S. Khalid, T. Zhara, S. Ansari, ${ }^{1}$ T. Farzana, ${ }^{1}$ T. Shamsi ${ }^{1}$ \\ Cure2Children Foundation, Florence, Italy, 'Pakistan Institute of Medical Sciences Children's \\ Hospital, Islamabad, ${ }^{2}$ National Institute of Blood Diseases, Karachi, Pakistan
}

\begin{abstract}
Thalassemia major (TM) is the most common deadly genetic disorder, a major cause of chronic non-infectious morbidity and financial burden in many low and middle-income regions. In these settings few children reach adulthood because proper long-term supportive care is seldom available. Bone marrow transplantation (BMT) is the only available curative modality and it can be very successful and cost-effective for young children with low-risk features and a compatible related donor. However, in countries where TM is most prevalent, there is a dire shortage of BMT centers. The Cure2Children Foundation has supported a feasibility study evaluating safety, efficacy and costs of developing a new BMT center in an underserved lower-middle-income country with relatively untrained professionals within a structured collaboration and knowledge-transfer program. A total of 24 consecutive patients who underwent BMT in Pakistan between September 2008 and August 2010 are included in this prospective analysis, 17 from an established bone marrow transplant center, the National Institute for Blood Diseases in Karachi, Pakistan and the initial 7 BMTs from a start up unit in a government civil hospital, the Pakistan Institute of Medical Sciences Children's Hospital in Islamabad. Patients were matched for age, nutritional status, growth, disease, disease status and post-BMT follow-up time. All patients had a matched-related sibling donor, were younger than 10 years of age at the time of transplantation, received the same conditioning regimen. All needy families could rely on a support program throughout the 8-month post-transplant period. The Cure2Children Foundation provided professional and financial support as well as a structured web-based data management and cooperation platform. At a median follow up of 19.6 months (range
\end{abstract}

Correspondence: L. Faulkner, Cure2Children Foundation, via Marconi 30, 50131 Florence, Italy.

Key words: transplantation developing countries.

Acknowledgements: This work was possible thanks to the support of Fondazione Monte dei Paschi di Siena, Italy.

(O) Copyright L. Faulkner et al., 2011

Licensee PAGEPress, Italy

Thalassemia Reports 2011; 1(s2):e9

doi:10.4081/thal.2011.s2.e9

This article is distributed under the terms of the Creative Commons Attribution Noncommercial License (by-nc 3.0) which permits any noncommercial use, distribution, and reproduction in any medium, provided the original author(s) and source are credited.

Parts of this work were presented at the "12th International Conference on Thalassemia and Hemoglobinopathies", Antalya (Turkey), 11-14 May 2011.
8.7 to 31.5 ) actuarial thalassemia-free survival is $85.6 \%$ and $85.7 \%$ and overall survival $94.1 \%$ and $85.7 \%$ in the established and start-up center respectively with no statistically significant differences. Other outcome indices like infectious complications, engraftment parameters, transplant-related complications, and post-BMT performance scores also did not differ. The median cost of matched-related transplants in the start-up center, including pre-BMT evaluation, was 11,513 USD (range 7,518 to 21,176). Within structured cooperation strategies bone marrow transplantation for thalassemia major can be performed safely, effectively, and affordably even in start-up centers in lower-middleincome countries, like Pakistan, were most thalassemia patients live. This observation may have important implications to increase access to cure for thalassemia worldwide.

\section{Introduction}

\section{Aslam's story}

Aslam is a 2 year and 3 months old boy with thalassemia major. His father is a mill worker and his mother a housewife, they live in interior Sindh, Pakistan. The father can read and write Sindhi (the local language). They need a 5-hour bus ride to the nearest thalassemia care center in Karachi were Aslam gets a transfusion once a month, the parents are aware they should go more often but it is very hard for them, the whole family income is less than 1,000 USD/year and a substantial part of it goes for the care of Aslam. Nine children have died of thalassemia in their extended family.

Aslam's doctor explained in Sindhi that an international NGO was supporting access to cure of thalassemia by bone marrow transplantation for needy families in Pakistan and presents this option to the parents because he has a 4 year-old healthy sister who could be the potential donor, even if she had thalassemia minor. The parents know that it will be very hard for them to provide Aslam with the long-term care he will need to be able to survive, they know and trust their doctors and decide to go for a cure even if they are aware that there is chance he may die from transplantation. The NGO will also provide accommodation and family support in Karachi.

Aslam's sister turns out to be compatible by HLA testing and three months later he is transplanted her bone marrow, he stays in hospital with his mom for a little over a month and then another 6 months with his family in the Karachi apartment provided by the NGO which also regularly sends a nice lady (herself cured by transplantation), to make sure they have the basic necessities and are able to keep the apartment clean.

Almost 8 months later they go back to their village, Aslam has not needed transfusions for over 7 months, his parents are very happy and grateful for their new life even though the doctor explained that he might have problems having children when he grows up. Prenatal diagnosis, should the mother expect another baby, was also discussed. 


\section{Thalassemia disease burden}

Thalassemia major is the most frequent deadly genetic defect worldwide and accounts for a substantial proportion of childhood mortality, morbidity and related healthcare expenses in many densely populated regions in North-Africa, Eastern Mediterranean, South-East Asia and Western Pacific where the carrier rate ranges from $3 \%$ to $40 \%{ }^{1,2}$

\section{Thalassemia outcomes in lower-income countries}

In spite of significant progress in supportive care, which may extend life expectancy well into adulthood, ${ }^{3}$ most patients in low to middleincome areas, where thalassemia is most prevalent, do not survive beyond 20 years of age and the risk of blood-borne infections, primarily hepatitis $\mathrm{C}$, is still substantial. ${ }^{4}$

\section{Bone marrow transplantation for thalassemia: accessibility and costs}

Bone marrow transplantation (BMT) remains the only definitive cure for thalassemia major with reported thalassemia-free survival rates consistently over $80 \%$ in selected young low-risk patients with a related histocompatible donor. ${ }^{5-7}$ BMT is also associated with improved quality of life $\mathrm{e}^{8,9}$ and is generally recommended in young low-risk patients with a matched related donor. ${ }^{10}$ In areas were thalassemia is endemic there is a severe shortage of centers for its cure. ${ }^{11,12}$ This is not only due to lack of financial resources, in fact BMT is less expensive compared to long-term supportive care, ${ }^{13}$ but other factors may contribute such as lack of specific professional expertise or the perception that setting up a BMT center is highly complex and expensive.

\section{The Cure2Children experience supporting BMT for thalassemia in Pakistan}

Cure2Children (C2C) is a non-profit and secular International NonGovernmental Organization founded by parents who lost their child to cancer. The mission of $\mathrm{C} 2 \mathrm{C}$ is to promote and support the care of children with malignancies and severe blood disorders directly in developing countries.

The Pakistan project originated from the passion, commitment and capacity of a Pakistani family with a thalassemic child transplanted in Italy by a team connected to $\mathrm{C} 2 \mathrm{C}$. The primary aim of this initiative has been to increase access to cure for children with thalassemia by capitalizing on available local expertise and facilities. The strategy relied on the prospective assessment of outcomes within a structured knowledge-transfer and support program applying common treatment protocols and standards for patient selection and management. We sought to assess if reported differences in outcome related to socio-economic conditions, are due primarily to patient selection, inconsistent or no access to appropriate drugs, lack of professional expertise, rather than to local conditions increasing the risk of infectious complications or causing poor family support and follow-up care. In addition we tested the hypothesis that within structured cooperation and assistance from third-party non-governmental organizations, like $\mathrm{C} 2 \mathrm{C}$, a relatively complex procedure like BMT could be set up safely and effectively with limited resources.

\section{Patient characteristics}

A total of 24 consecutive patients with transfusion-dependent thalassemia transplanted in Pakistan between September 2008 and August 2010 were included in the analysis. Selection criteria included age less than 10 years, no hepatomegaly (liver $<2 \mathrm{~cm}$ from the right costal mar- gin on physical examination), availability of an HLA-matched suitable related donor, clear understanding of the risks and benefits of transplant, informed consent, and no major infectious diseases or other conditions affecting transplant outcome. Hepatitis C positivity was not considered an exclusion criteria. Eligibility also required serum creatinine, bilirubin and transaminase less than twice normal values, normal chest x-ray and echocardiogram, normal age-appropriate performance scale and institutional commitment to sharing patient data on a daily basis and according to privacy regulations. Liver biopsy was not considered mandatory and absence of significant hepatomegaly was deemed sufficient to exclude high transplant-related risk. Thus, according to the standard Pesaro risk assignment, ${ }^{5}$ these patients would be considered class I or II and have an expected cure rate with BMT of at least $85 \%{ }^{14}$

Within this group, 17 patients were transplanted in an established private hospital, the National Institute of Blood Diseases in Karaci (NIBD), and 7 at a start-up unit developed by C2C at the Children's Hospital of the Pakistan Institute of Medical Sciences (PIMS), a large government hospital in Islamabad. This 2-bedded newly developed BMT service, the Simone Montomoli Bone Marrow Transplant Unit, was created in a 150 square meter total space provided by the hospital administration and renovated with less than 50,000 USD, including basic equipment. Institutions signed formal agreements with the $\mathrm{C} 2 \mathrm{C}$ specifying the above selection criteria and treatment protocol. All patients were admitted in single rooms with split air conditioning, private bathrooms and daily cleaning. Positive pressure gradients or centralized HEPA filtration systems were not considered mandatory while blood product irradiation, cyclosporin blood level monitoring and cytomegalovirus (CMV) reactivation assessment, by either pp65 antigenemia or real-time PCR, were required. Hand washing was strictly enforced, however while wearing gloves and gowns this was not.

The two patient groups were matched for age, growth and nutrition, diseases, disease status, graft type, conditioning, GVHD/rejection prophylaxis and post-BMT follow-up time (Table 1).

\section{Bone marrow transplant procedure}

The following conditioning regimen was utilized: Busulfan $3.5 \mathrm{mg} / \mathrm{kg}$ day in 4 divided doses on days - 10 to -7 (total dose $14 \mathrm{mg} / \mathrm{kg}$ ), Thiotepa $10 \mathrm{mg} / \mathrm{kg} /$ day in two divided doses on day -6 (total dose $10 \mathrm{mg} / \mathrm{kg}$ ), and Cyclophosphamide $50 \mathrm{mg} / \mathrm{kg}$ day once daily on days -5 to -2 (total dose $200 \mathrm{mg} / \mathrm{kg}$ ) followed by the infusion of freshly harvested HLA-compatible bone marrow on day 0 . GVHD prophylaxis consisted of cyclosporin A starting at $5 \mathrm{mg} / \mathrm{kg}$ i.v. from day -2 to +5 than $3 \mathrm{mg} / \mathrm{kg}$ i.v. from day +6 to +22 to be followed by $10 \mathrm{mg} / \mathrm{kg} /$ day in two daily oral doses for up to day +90 after which it was tapered by $-5 \%$ /week and discontinued at 7 8 months post-BMT unless otherwise indicated. A short methotrexate course consisting of $10 \mathrm{mg} / \mathrm{msq}$ i.v. on days +1 (24 hours after marrow infusion), +3 and +6 , with folinic acid rescue at 24 hours after each methotrexate with 3 doses of $10 \mathrm{mg} / \mathrm{msq}$ i.v. at 8 hour intervals, i.e. at hours $+24 \mathrm{~h}+32 \mathrm{~h}$ and $+40 \mathrm{~h}$. Methylprednisolone at $0.5 \mathrm{mg} / \mathrm{kg} / \mathrm{day}$ i.v. from day -1 to +30 and tapered by $-1 / 3$ every 5 days over 15 days and stopped on day +45 is also used.

\section{Infection control, treatment and prophylaxis}

For anti-helminthic prophylaxis mebendazole $100 \mathrm{mg}$ twice daily for three days was administered before conditioning. For candida infection prevention fluconazole $3-6 \mathrm{mg} / \mathrm{kg} /$ day as a single dose was used and for herpes virus acyclovir $250-500 \mathrm{mg} / \mathrm{m}^{2} /$ dose three times a day, both drugs were administered from day +1 to +90 . CMV reactivation was monitored weekly from day +15 to +90 post-BMT. No routine antibacterial prophylaxis was used. For antifungal therapy amphotericin B was considered the first-line drug and voriconalzole second line. For CMV activation (any antigenemia positivity or > 500 CMV DNA copies/ml) 
both ganciclovir and foscarnet were available. Co-trimoxazole at 5 $\mathrm{mg} / \mathrm{kg} /$ dose twice daily for three consecutive days a week was administered for Pneumocystis prophylaxis from the day neutrophil counts reach $500 / \mathrm{mcl}$ to day +90 .

\section{Family support program}

A patient coordinator as well as housing and monthly allowance was provided by $\mathrm{C} 2 \mathrm{C}$. This family support program was implemented throughout the eight months post BMT.

\section{Collaboration methodology}

Structured cooperation and communication strategies involving international and national transplant specialists were employed. Management standards for therapy administration, central venous access, severe pancytopenia, immunosuppression, and hospital infection control were addressed by local training, a specific web-based open-source data management software developed by C2C (CDATA, www.cure2children.org/ws/thdb) and Skype videoconferencing (www.skype.com). Patient-specific treatment plans were provided as Microsoft Excel-generated pre-calculated treatment sheets meant to reduce the physician's workload and prescription errors and also to supply nurses with clearly written order sheets in keeping with good clinical practices.

\section{Statistical analysis}

Statistical analysis was perfomed using GraphPad Prism software version 5 March 2007 (www.graphpad.com/prism/Prism.htm). Kaplan-Meier survival curves were compared by Log-rank (Mantel-Cox) Test and patient characteristics by Mann-Whitney nonparametric test using twotailed P Anthropometric z-score values were calculated with the World Health Organization shareware Anthro. ${ }^{15}$ For patients above 60 months of age WHO Child Growth Standards reference tables were used. ${ }^{16}$

At a median follow up of 20 months (range 10.9 to 31.5 ) and 17.7 (range 8.7 to 24.2) for patients managed in an established unit or in a start-up unit respectively, no significant difference in outcomes was observed with actuarial thalassemia-free survival of $85.6 \%$ and $85.7 \%$ ( $\log$ rank $P$ 0.8609) and overall survival $94.1 \%$ and $85.7 \%$ (log rank $P$ $0.5322)$ respectively.

\section{Discussion}

To our knowledge this is the first study prospectively comparing homogeneous patient groups undergoing bone marrow transplantation in start-up versus established BMT centers in low-resource settings in the context of a structured knowledge-transfer strategy. The objective of this study, in keeping with the mission of the $\mathrm{C} 2 \mathrm{C}$, was to assess the potential to extend access to BMT for severe hematological disorders in underserved regions.

There is general perception that bone marrow transplant centers need complex engineering standards requiring undue investments, even more in poor countries were infectious risk may be higher. In fact there is no evidence that the latter is true. ${ }^{17-19}$ Even if available international guidelines call for placement of allogeneic BMT recipients in highly protected environments with positive pressure gradients, intensive air exchange and filtration, ${ }^{20}$ these recommendations are not based on well-designed clinical trials. In fact, safe care of allogeneic transplantation recipients has been reported even in the outpatient setting. ${ }^{21,} 22$ Many widely held practices which may unnecessarily increase BMT-related expenses are being reconsidered worldwide and cost-containment considerations are even more important in settings with more limited resources.
Table 1. Characteristics of patients treated at the established institution (NIBD) versus a start up service (PIMS).

\begin{tabular}{lccc} 
& Established Unit & Start-up Unit & P \\
Age (years) & $3.5(1.8$ to 9.4$)$ & $3.0(0.9$ to 5.4$)$ & 0.43 \\
Gender & $8 \mathrm{M}, 9 \mathrm{~F}$ & $6 \mathrm{M}, 1 \mathrm{~F}$ & \\
\hline Height for age (z-score) & $-0.82(-3.47$ to 1.92$)$ & $-1.17(-2.48$ to 0.72$)$ & 0.94 \\
Weight for age (z-score) & $-0.51(-3.55$ to 0.73$)$ & $-0.72(-2.60$ to 0.12$)$ & 0.43 \\
\hline Body mass index (z-score) & $-0.11(-2.78$ to 1.68$)$ & $-0.71(-2.49$ to 0.77$)$ & 0.53 \\
Pre-BMT Ferritin & $1200(289$ to 2960$)$ & $2476(616$ to 8008$)$ & 0.58 \\
\hline Consanguinity & $14 / 17(82 \%)$ & $5 / 7(71 \%)$ & \\
Donor thalassemia minor & $10 / 17(59 \%)$ & $6 / 7(86 \%)$ & \\
\hline Nucleated cell dose/kg x10 & $8.6(1.4$ to 23$)$ & $5.8(3.1$ to 8.0$)$ & 0.27 \\
Follow up from BMT (months) & $20(10.9$ to 31.5$)$ & $17.7(8.7$ to 24.2$)$ & 0.59 \\
\hline
\end{tabular}

Table 2. Engraftment data.

\begin{tabular}{lccc} 
& Established Unit & Start-up Unit & P \\
Median day ANC $>$ 500/ $\mu \mathrm{L}$ & $19.5(12-35)$ & $15(10-23)$ & 0.15 \\
Median day Plt $>20.000 / \mu \mathrm{L}$ & $22.5(10-49)$ & $15.5(12-20)$ & 0.07 \\
\hline Median n. Plt transfusions & $6.5(1-26)$ & $4(1-18)$ & 0.25 \\
Median n. RBC transfusions & $2(1-6)$ & $2(0-7)$ & 0.47 \\
\hline Last RBC transfusion day & $12.5(1-36)$ & $16(0-152)$ & 0.59 \\
Median discharge day post-BMT & $26(12-60)$ & $38.5(22-109)$ & 0.02 \\
\hline
\end{tabular}

Table 3. Summary of adverse events.

\begin{tabular}{lcc} 
Infections & Established Unit & Start-up Unit \\
CMV activation & $7(41 \%)$ & $3(43 \%)$ \\
Aspergillosis (probable or proven) & 0 & 0 \\
\hline Fever and neutropenia & $11(65 \%)$ & $4(67 \%)$ \\
Tuberculosis (probable) & $1(6 \%)$ & $1(14 \%)$ \\
\hline Acute GVHD grade 1-2 & $1(6 \%)$ & $2(29 \%)$ \\
Acute GVHD grade 3-4 & 0 & $2(29 \%)$ \\
\hline Limited chronic GVHD & $1(6 \%)$ & $1(14 \%)$ \\
Extensive chronic GVHD & 0 & 0 \\
\hline Hemorrhagic cystitis & $2(17 \%)$ & $1(14 \%)$ \\
Mucositis (> ECOG grade 1) & $5(29 \%)$ & $2(28 \%)$ \\
\hline Death & $1(6 \%)$ & $1(14 \%)$ \\
\hline
\end{tabular}

Table 4. Cost comparison. Pakistan costs obtained from the seven transplants performed in the start-up unit in a government hospital, all patients had at least 8 months follow up post-BMT.

\begin{tabular}{lc} 
Pre-Transplant evaluation & $\begin{array}{c}\text { Start-up Unit } \\
\text { Median (range) }\end{array}$ \\
Diagnostic & $\$ 532(141-1,026)$ \\
\hline Blood products & $\$ 1,704(733-4,548)$ \\
Hospitalization charges & $\$ 132(88-374)$ \\
\hline Surgical devices (CVL) & $\$ 535(455-1,320)$ \\
Drugs & $\$ 396(311-437)$ \\
\hline Professional Cost & $\$ 1,577(1,212-5,518)$ \\
Follow up cost & $\$ 4,324(3,817-10,660)$ \\
\hline Total & $\$ 1,714(375-2,350)$ \\
\hline
\end{tabular}


In this study patients and their caretakers were admitted to single rooms with private bathrooms and split air conditioning. Strict hand washing of all personnel and visitors was enforced and BMT units were cleaned daily.

Infectious complications observed in Pakistani centers did not seem to be substantially different from those encountered in Europe or North America, with the exception of two possible cases of probable pulmonary tuberculosis. CMV reactivation was the main opportunistic infection observed. Of the two centers participating in this project one was a newly developed service heavily relying on initial local training followed by daily interaction via video-conferencing and web-based data management, the second an established BMT service which had been performing transplantation for 8 years.

This experience may set a useful precedent to extend access to bone marrow transplantation in lower-middle income regions and limit the emigration of thalassemia major patient to richer countries or even increase attraction of patients from abroad. In our experience BMT outcomes in low-risk cases with a compatible related donor were comparable to those obtained in high-income countries but with one-tenth of the costs.

Given the great case load, high success rates and much lower costs, thalassemia BMT programs in developing countries may achieve high standards of care, international competiveness and self-sustainability. This may not only contribute to boost advances in the cure of thalassemia worldwide but also to increase access to BMT for other lifethreatening diseases such as severe aplastic anemia and high-risk leukemia, and contribute to biomedical research. The prospect of cure may also increase the attraction of affected families and increase opportunities to cascade screening and prevention programs ${ }^{23}$ as well as improve compliance with supportive care.

The lower than expected incidence of severe acute and chronic GVHD in Pakistani patients might be attributable to consanguinity resulting in reduced minor HLA disparities as well as on effects due to ethnicity. ${ }^{24}$

This study, in addition to the establishment of a proof of principle with potential important effects on increasing the number of BMT centers and empowerment of tertiary medical care in developing countries, might also be relevant to health care cost containment, comparativeeffectiveness assessments, and current practices of bone marrow and stem cell transplantation worldwide.

\section{References}

1. Modell B, Darlison M. Global epidemiology of haemoglobin disorders and derived service indicators. WHO website; 2009. Available at: http://www.who.int/bulletin/volumes/86/6/06-036673_.

2. Weatherall DJ. The inherited diseases of hemoglobin are an emerging global health burden. Blood. 2010;115:4331-4336.

3. Rund D, Rachmilewitz E. $\beta$-thalassemia. N Engl J Med. 2005;353:1135-1146.

4. Akhtar S, Moatter T. Hepatitis C virus infection in polytransfused thalassemic children in Pakistan. Indian Pediatr. 2004;41:10721073 .

5. Lucarelli G, Galimberti M, Polchi P, et al. Bone marrow transplantation in patients with thalassemia. NEJM. 1990;322:417-421.

6. Sabloff M, Chandy M, Wang Z, et al. HLA-matched sibling bone marrow transplantation for $\beta$-thalassemia major. Blood. 2011;117:1745-1750.

7. Angelucci E. Hematopoietic stem cell transplantation in thalassemia. Hematology. 2010;:456-462.

8. Caocci G, Efficace F, Ciotti F, et al. Prospective assessment of health related quality of life in pediatric $\beta$-thalassemia patients following hematopoietic stem cell transplantation. Biol. Blood Marrow Transplant. 2010. Available at: http://www.ncbi.nlm.nih.gov/pubmed /20870029. Accessed May 2, 2011.

9. Cheuk DK, Mok AS, Lee AC, et al. Quality of life in patients with transfusion-dependent thalassemia after hematopoietic SCT. Bone Marrow Transplant. 2008;42:319-327.

10. Cappellini MD, Cohen A, Eleftheriou A, et al. Guidelines for the clinical management of thalassaemia 2nd edition revised (2008). 2nd ed. Thalassemia International Federation; 2008. Available at: http://www.thalassaemia.org.cy/pdf/Guidelines_2nd_revised_ edition_EN.pdf. Accessed April 7, 2010.

11. Aljurf MD, Zaidi SZ, El SH, et al. Special issues related to hematopoietic SCT in the Eastern Mediterranean region and the first regional activity report. Bone marrow transplant. 2009;43:1-12.

12. Chandy M. Stem cell transplantation in India. Bone marrow transplant. 2008;42:S81-S84.

13. Riewpaiboon A, Nuchprayoon I, Torcharus K, et al. Economic burden of $\beta$-thalassemia/Hb $\mathrm{E}$ and $\beta$-thalassemia major in Thai children. BMC.Res.Notes. 2010;3:29.

14. Gaziev J, Sodani P, Lucarelli G. Hematopoietic stem cell transplantation in thalassemia. Bone marrow transplant. 2008;42:S41.

15. Anon. WHO I WHO Anthro (version 3.2.2, January 2011) and macros. Available at: http://www.who.int/childgrowth/software/en/. Accessed May 4, 2011.

16. Anon. WHO I The WHO Child Growth Standards. Available at: http://www.who.int/childgrowth/en/. Accessed April 9, 2010.

17. Kumar R, Naithani R, Mishra P, et al. Allogeneic hematopoietic SCT performed in non-HEPA filter rooms: initial experience from a single center in India. Bone marrow transplant. 2009;43:115-119.

18. George B, Mathews V, Viswabandya A, Srivastava A, Chandy M. Infections in children undergoing allogeneic bone marrow transplantation in India. Pediatr.Transplant. 2006;10:48-54.

19. Giebel S, Labopin M, Ehninger G, et al. Association of Human Development Index with rates and outcomes of hematopoietic stem cell transplantation for patients with acute leukemia. Blood. 2010;116:122-128.

20. Anon. Guidelines for preventing infectious complications among hematopoietic cell transplant recipients: a global perspective. Bone Marrow Transplant. 2009;44:453-558.

21. Svahn BM, Remberger M, Myrbäck KE, et al. Home care during the pancytopenic phase after allogeneic hematopoietic stem cell transplantation is advantageous compared with hospital care. Blood. 2002;100:4317-4324.

22. Solomon SR, Matthews RH, Barreras AM, et al. Outpatient myeloablative allo-SCT: a comprehensive approach yields decreased hospital utilization and low TRM. Bone Marrow Transplant. 2010;45:468-475.

23. Ahmed S, Saleem M, Modell B, Petrou M. Screening extended families for genetic hemoglobin disorders in Pakistan. NEJM. 2002;347:1162-1168.

24. Oh H, Loberiza FR, Zhang MJ, et al. Comparison of graft-versushost-disease and survival after HLA-identical sibling bone marrow transplantation in ethnic populations. Blood. 2005;105:1408-1416. 